\title{
The Relationship between Unilateral Dynamic Stability and Multidirectional Jump Performance in Team Sport Athletes
}

\author{
Robert G. LOCKIE $^{1} \bullet$ Farzad JALILVAND $^{1}$ \\ Corrin A. JORDAN ${ }^{2} \bullet$ Samuel J. CALLAGHAN ${ }^{3} \bullet$ Matthew D. JEFFRIESS $^{4}$ \\ Tawni M. LUCZO ${ }^{5}$ Adrian B. SCHULTZ ${ }^{2}$
}

7 his study investigated relationships between dynamic stability and multidirectional jumping. A modified Star Excursion Balance Test (mSEBT), incorporating unilateral lower-body reaching in posteromedial, medial, and anteromedial directions, assessed dynamic stability. Unilateral vertical (VJ), standing broad (SBJ) and lateral jumps (LJ) assessed leg power. VJ power and relative SBJ and LJ distances were calculated. Thirty-two team sport athletes completed the mSEBT when each leg was used for stance, and leftand right-leg VJ, SBJ, and LJ. Correlations were drawn between data recorded from each leg when used for mSEBT stance and for each jump. Participants were dichotomized into better and lesser dynamic stability groups according to the sum of excursions for each leg. A one-way ANOVA determined mSEBT and jump differences $(p<0.05)$. The left-leg posteromedial and medial excursions correlated with VJ power; the medial excursion correlated with the LJ. The right-leg posteromedial excursion correlated with the SBJ; the anteromedial excursion correlated with the SBJ, and relative SBJ and LJ $(\mathrm{r}=0.35-0.45)$. There were no differences in unilateral jumping between the better and lesser groups. Although there is some relationship with dynamic stability, this study further highlighted the complex interaction between the physical and technical characteristics of multidirectional jumping.

Keywords: Star Excursion Balance Test, functional reaching, vertical jump power, lateral jump, standing broad jump

\footnotetext{
${ }^{1}$ Department of Kinesiology, California State University, Northridge, Northridge, USA

${ }^{2}$ Exercise and Sport Science Department, School of Environmental and Life Sciences, University of Newcastle, Ourimbah, Australia

${ }^{3}$ School of Exercise and Health Sciences, Edith Cowan University, Joondalup, Australia

${ }^{4}$ Faculty of Health, University of Technology, Sydney, Lindfield, Australia

${ }^{5}$ Department of Kinesiology, California State University of Monterey Bay, Seaside, USA
} 


\section{Introduction}

Athletes participating in team sports are required to cut, sprint, and jump in multiple directions. Two elements that influence an athlete's ability to do this effectively are dynamic stability and leg power (Kovacs et al., 2008; Lockie et al., 2014b; Sheppard and Young, 2006). With regards to dynamic stability, this is the ability to maintain balance while transitioning between static and dynamic movement states (Wikstrom et al., 2005). Athletes with good dynamic stability should be able to maintain a stable center of gravity during sport-specific movements, such as multidirectional sprinting (Lockie et al., in press). With this in mind, it is important to identify and define an appropriate dynamic stability assessment for use in team sport athletes.

One of the more commonly used dynamic stability assessments is the Star Excursion Balance Test (SEBT) (Gribble et al., 2012). The SEBT can assess dynamic stability through the use of functional reaching of the lower limbs, and has been shown to be valid and reliable (Gribble, 2003; Hertel et al., 2000). This test typically involves a participant assuming a unilateral stance and performing eight single-leg squats while maximally reaching in three anterior, two lateral, and three posterior directions. Hertel et al. (2006) has argued that the majority of these excursions are redundant as they measure the same capacity, and that only the anteromedial, medial, and posteromedial reaches best represent the SEBT. Indeed, a modified version of the SEBT (mSEBT) using those excursions has been previously utilized to monitor dynamic stability changes following speed, agility, and plyometrics training (Lockie et al., 2014b). Therefore, the mSEBT should provide a specific assessment of unilateral dynamic stability in team sport athletes.

Jump performance is often used to indirectly measure leg power, given that power incorporates the ability to produce force quickly (Lockie et al., 2014a). This is a necessary component of performing an ideal jump. There is a complex interaction between physiological, biomechanical, and technical factors that interact within multidirectional jumping and power-based actions. Research has documented lower-body strength (Alemdaroglu, 2012; Baker and Nance, 1999; Wisløff et al., 2004), rate of force development (Häkkinen and Komi, 1985; Häkkinen et al., 1986), elastic energy use (Häkkinen et al., 1986; Harrison et al., 2004), leg stiffness (Harrison et al., 2004; Hunter and Marshall, 2002; Pruyn et al., 2014), and proper coordination and technique (Bobbert and van Ingen Schenau, 1988; Harman et al., 1990; Hudson, 1986) can all contribute to successful jump performance. This would be true for both bilateral and unilateral jumps. However, during a unilateral jump, an athlete must rapidly express their strength through force development while in single-leg support. This places greater stress 
on the capacity to maintain stability while completing the jump. However, the relationship between dynamic stability and unilateral jump performance and power has received limited analysis within the literature.

The only investigation of the interaction between unilateral dynamic stability and leg power was conducted by Lockie et al. (2013b). Lockie et al. (2013b) found significant relationships $(\phi<0.05$; correlation coefficient $[\mathrm{r}]=$ 0.514-0.823) between selected excursions, including the posteromedial and medial reaches, with lateral jumps for both legs in male recreational team sport athletes. However, dynamic stability relationships with unilateral vertical and standing broad jumps were not investigated in this study. This is notable, as previous research has established the specificity of unilateral jump assessments with regards to direction (i.e. vertical, horizontal, or lateral) (Brughelli et al., 2008; Lockie et al., 2014a; Meylan et al., 2009). Therefore, the potential influence of dynamic stability on single-leg vertical and horizontal jump performance should be investigated. This is important for team sport athletes, given their need for sport-specific multidirectional movements. Indeed, if a team sport athlete can maintain greater dynamic stability prior to taking off for a single-leg jump, they would be more likely to produce an appropriate countermovement range of motion so as to project further (Domire and Challis, 2007), no matter the direction. It is important for the relationship between unilateral dynamic stability and multidirectional jumping for each leg to be elucidated by appropriate research.

Therefore, this study investigated relationships between performance in an $\mathrm{mSEBT}$ incorporating the anteromedial, medial, and posteromedial reaches as a measure of dynamic stability, with performance in unilateral vertical, standing broad, and lateral jumps. Power was also calculated for the vertical jump, while the standing broad and lateral jumps were made relative to body mass for further analysis. Although leg dominance can influence a movement such as jumping (McElveen et al., 2010), previous research has suggested leg dominance can be specific to balance tasks and different to that of dynamic movements (Gstottner et al., 2009; McCurdy and Langford, 2006; McGrath et al., 2015), such as a jump. As a result, this study focused on investigating the jump and dynamic stability characteristics of each leg (i.e. the left and right legs), rather than documenting the dominant and non-dominant legs, as this could vary across the different assessments. Correlations were drawn individually for each leg when it was used for stance in the mSEBT, and for jump performance data. To further investigate the relationships between the mSEBT and jumping, participants were split in better and lesser dynamic stability groups to identify whether unilateral jump performance also differed between the groups. It was hypothesized that there would be significant relationships between mSEBT and 
jump heights, distances, power, and relative measures, and the better dynamic stability group would perform better in the jumps. Establishing relationships between dynamic stability and unilateral jumping could demonstrate how much dynamic stability could contribute to single-leg power generation, and whether these capacities could be developed concurrently with certain exercises. This would be beneficial to team sport athletes who need to produce multidirectional movements during game-play.

\section{Methods}

\section{Participants}

Thirty-two male recreational team sport athletes (age $=22.84 \pm 3.90$ years; height $=1.79 \pm 0.07$ meters $[\mathrm{m}]$; mass $=79.37 \pm 12.49$ kilograms) volunteered for this study. Participants were recruited if they: (a) were 18 years of age or older; (b) currently participated in a team sport (e.g. soccer, basketball, rugby, Australian football); (c) had a team sport training history ( $\geq$ two times per week) that extended over the previous year; (d) were currently training for a team sport ( $\geq$ three hours per week); and (e) did not have any medical conditions compromising participation. Even though there may be certain differences in traits between different sport participants, the analysis of performance with regards to physical characteristics common to athletes from assorted team sports has been previously conducted, as physical capacities such as dynamic stability and leg power are common to these sports (Lockie et al., 2014a; Lockie et al., in press; Sassi et al., 2009; Spinks et al., 2007; Spiteri et al., 2013). Testing occurred during the competition season for all participants. The institutional ethics committee approved the methodology and procedures used in this study. All participants received a clear explanation of the study, including the risks and benefits, and written informed consent was obtained prior to testing.

\section{Procedures}

Testing occurred over two days, separated by 48 hours, with each session lasting for approximately 30 minutes. The first testing session involved the unilateral jump assessments; the second session the mSEBT. All assessments were conducted in the biomechanics laboratory at the university. Participants were tested at the same time of day for both sessions, did not eat for 2-3 hours prior to their sessions, and refrained from intensive exercise in the day prior to testing. A standardized warm-up, which consisted of five minutes of jogging on a treadmill at a self-selected velocity, five minutes of dynamic stretching of the legs, and practice jumps or excursions, were used for all participants in each testing session (Lockie et al., 2013b). Prior to data collection in testing session 
one, the participant's age, height, and body mass were recorded. Height was measured using a stadiometer (Ecomed Trading, Seven Hills, Australia) and recorded to the nearest 0.01 centimeters. Body mass was recorded using electronic digital scales (Tanita Corporation, Tokyo, Japan). The jumps were performed in this order: vertical, standing broad, then lateral jumps. However, the order of which leg was tested first within each jump condition was randomized between participants. This followed procedures established in the literature (Lockie et al., 2014a; Lockie et al., 2015a; Lockie et al., 2015b). Three trials were performed for each leg, two minutes recovery was provided between each trial, and the average of jump performance was used for analysis.

\section{Unilateral Vertical Jump}

The vertical jump was used as an indirect measure of leg power in the vertical plane. A Yardstick apparatus (Swift Performance Equipment, Wacol, Australia) was used to measure jump performance. The use of this type of equipment is common for athlete assessment in the field (Burr et al., 2007; Gabbett and Seibold, 2013; Kuzmits and Adams, 2008; Lockie et al., 2012b; Lockie et al., 2015a; Lockie et al., 2015b; McClenton et al., 2008; Robbins, 2010), and thus was adopted in this study. The participant initially stood side-on to the Yardstick (on the participants' dominant upper-limb side), and while keeping his heels on the floor, reached upward as high as possible, fully elevating the shoulder to displace as many vanes as possible. The last vane moved was recorded as the participant's standing reach height and zero reference. The jump involved the participant leaping as high as possible using a one-foot take-off, with no preparatory step, and then landing on both feet. Height was recorded in centimeters from highest vane moved, by subtracting the standing reach height from the jump height, and converted to meters. No restrictions were placed on the knee angle during the eccentric phase of the jump. The procedures used for this jump, with a countermovement freely chosen by participants and the contribution of arm swing, have been adopted previously within the literature (Lockie et al., 2014a; Lockie et al., 2015a; Lockie et al., 2015b; McCurdy et al., 2005; Newton et al., 2006). All participants were instructed to use a countermovement; if they did not, the trial was disregarded and reattempted. Power output was also calculated from the mean vertical jump data by using the Lewis formula: Power $\left(\mathrm{kg} \cdot \mathrm{m} \cdot \mathrm{s}^{-1}\right)$

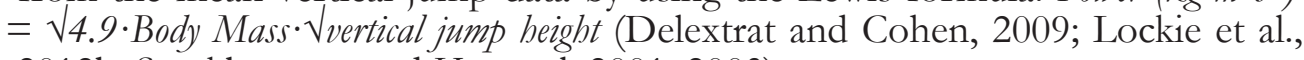
2012b; Stockbrugger and Haennel, 2001, 2003).

\section{Unilateral Standing Broad Jump}

The standing broad jump was used as an indirect measure of horizontal power, and is a common field test for a range of team sports (Kuzmits and 
Adams, 2008; Lockie et al., 2014a; Lockie et al., 2012b; Lockie et al., 2015a; Lockie et al., 2015b; Markovic, 2007; Meylan et al., 2009; Peterson et al., 2006; Robbins, 2010). The participant placed the toes of both feet on the back of the start line, before balancing on the leg to be tested. With a simultaneous arm swing and crouch, the participant leaped as far forward as possible, taking off from one leg, before landing on two feet (Lockie et al., 2014a; Lockie et al., 2015a; Lockie et al., 2015b; Meylan et al., 2009). Participants had to 'stick' the landing for the trial to be counted. If this was not done, the trial was disregarded and another was attempted after the required rest period. Participants were instructed to use a countermovement, and no restrictions were placed on body angles attained during the preparatory phase of the jump or the arm swing used, which was as per the unilateral vertical jump (Lockie et al., 2014a; Lockie et al., 2015a; Lockie et al., 2015b; McCurdy et al., 2005; Newton et al., 2006). The distance was measured to the nearest $0.01 \mathrm{~m}$ using a standard tape measure (HART Sport, Aspley, Australia), perpendicular from the front of the start line to the posterior aspect of the back heel at the landing (Lockie et al., 2014a; Lockie et al., 2015a; Lockie et al., 2015b; Peterson et al., 2006; Robbins, 2010). For further analysis, the mean standing broad jump distance for each leg was made relative to body mass via the formula: relative standing broad jump $=$ jump distance $\div$ body mass (Lockie et al., 2012a; Stockbrugger and Haennel, 2003).

\section{Lateral Jump}

Lateral jump performance was used as an indirect measure of lateral power for each leg. The lateral jump has also been used for field testing in team sport athletes (Delaney et al., in press; Lockie et al., 2015a; Lockie et al., 2015b; Lockie et al., 2013b; Mornieux et al., 2014), so thus was included in this research. The participant started by standing on the testing leg with the medial border of the foot of the leg being tested level with the start line (Lockie et al., 2014a; Lockie et al., 2015a; Lockie et al., 2015b; Meylan et al., 2009), and self-selected the preparatory crouch distance. Participants then jumped laterally to the inside, and landed on two feet. To be consistent with the other jump tests (Lockie et al., 2014a; Lockie et al., 2015a; Lockie et al., 2015b; McCurdy et al., 2005; Newton et al., 2006), participants were instructed to use a countermovement, and no restrictions were placed on the arm swing used or the range of the countermovement. The distance jumped was measured with a standard tape measure (HART Sport, Aspley, Australia) to the nearest $0.01 \mathrm{~m}$, perpendicular from the start line to the lateral margin of the take-off leg (Delaney et al., in press; Lockie et al., 2014a; Lockie et al., 2015a; Lockie et al., 2015b; Lockie et al., 2013b). If participants did not 'stick' the landing and over-balanced, the trial was disregarded and reattempted. Lateral jump distance for each leg was also made relative to body mass via the formula: relative lateral jump $=$ jump distance $\div$ body 
mass (Lockie et al., 2012a; Stockbrugger and Haennel, 2003).

\section{Modified Star Excursion Balance Test (mSEBT)}

Dynamic balance was assessed by using the mSEBT through three excursions; posteromedial, medial, and anteromedial (Figure 1). As stated, these excursions are the most representative of the SEBT (Hertel et al., 2006), and have been used previously in team sport athlete research (Lockie et al., 2014b). The testing grid consisted of standard, $120-\mathrm{cm}$ long, tape measures taped to the laboratory floor. Each tape measure extended from an origin at $45^{\circ}$ increments, which was measured by a goniometer. Participants stood on the center marker of the mSEBT, with the ankle malleoli aligned with the lateral tape measures, which was visually assessed by the researcher. Participants then used their free leg to reach in the afore-mentioned order. With each attempt, the participant attempted to reach as far as possible along each line and make a light touch on the ground with the most distal part of the reaching leg. The participant then returned the reaching leg to a bilateral stance, without allowing contact to affect overall balance. A researcher noted the reach distance after each attempt. Participants placed their hands on their hips during the mSEBT, and were required to keep them there throughout all reach attempts. A trial was disregarded if the researcher felt the participant used the reaching leg for an extended period of support, removed the stance leg from the center of the grid, removed their hands from their hips, or was unable to maintain balance. A minimum of three practice trials were used prior to data collection to familiarize participants to the movements required, and to serve as a warm-up. The order of the stance leg used during testing was randomized across participants. Reach distances were considered relative to leg length, and expressed as a percentage according to the formula relative reach distance $=$ reach distance/leg length $\times 100$ (Gribble and Hertel, 2003; Lockie et al., in press). 

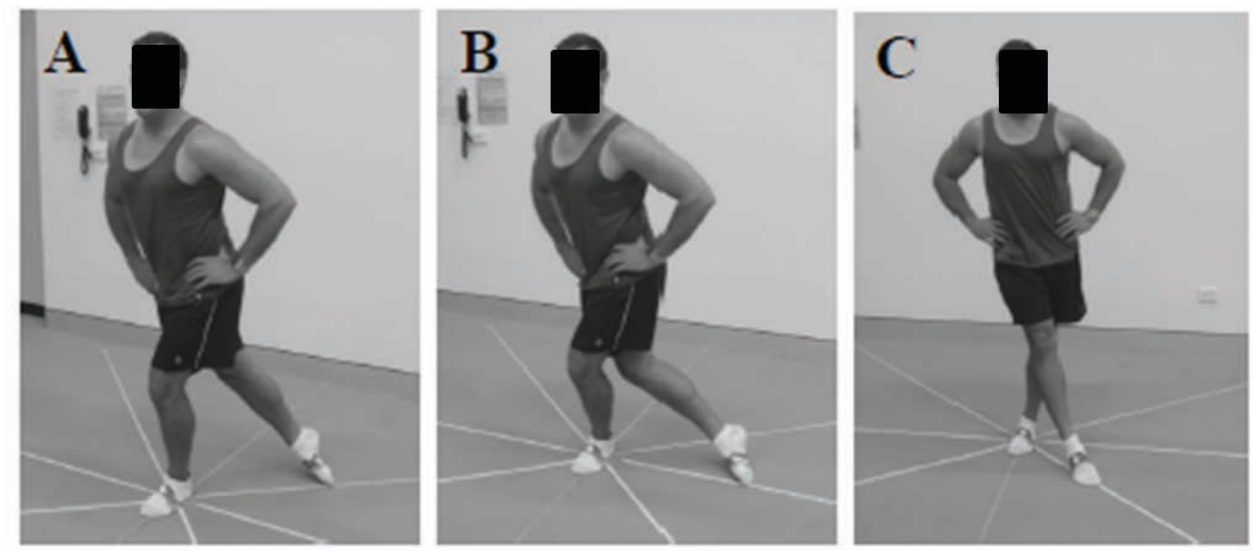

Figure 1. Modified Star Excursion Balance Test performance with a left stance leg and right reach leg for the (A) posteromedial; (B) medial; and (C) anteromedial excursions.

\section{Statistical Analysis}

All statistics were computed using the Statistics Package for Social Sciences Version 22.0 (IBM, Armonk, United States of America). Descriptive statistics (mean \pm standard deviation) were used to profile each measured parameter. Pearson's two-tailed correlation analysis determined relationships within each leg individually when it was the stance leg in the mSEBT, and for the vertical, standing broad, and lateral jumps (i.e. the left-leg stance mSEBT excursions were only correlated with left-leg jumps, and the same for the right leg). Data was pooled for all participants $(\mathrm{n}=32)$, with significance set at $\mathrm{p} \leq 0.05$. The strength of the correlation was designated as: an $\mathrm{r}$ value between 0 to 0.3 , or 0 to -0.3 , was considered small; 0.31 to 0.49 , or -0.31 to -0.49 , moderate; 0.5 to 0.69 , or -0.5 to -0.69 , large; 0.7 to 0.89 , or -0.7 to -0.89 , very large; and 0.9 to 1 , or -0.9 to -1 , near perfect for predicting relationships (Hopkins, 2009).

Participants were then dichotomized into better and lesser dynamic stability groups according to the sum of excursion distances for the posteromedial, medial, and anteromedial reach distances adjusted for leg length. To ensure that the groups were composed of participants with different levels of dynamic stability, a cut-off point was established through the formula mean $+(0.2 \times$ standard deviation of the mean) (Lockie et al., 2014a; Lockie et al., 2013a). Multiplying the between-participants standard deviation by 0.2 provides the smallest worthwhile 
change in the mean for this sample (Hopkins, 2004). Within the context of the current study, by providing a cut-off point above the summed mSEBT reaches should ensure that participants above this value would be superior. Therefore, participants above this cut-off point were placed in the better group; participants below this were placed in the lesser group. A one-way analysis of variance ( $p$ $\leq 0.05)$ calculated significant differences between the dependent variables (i.e. excursion distances, unilateral jump heights and distances). Groups were defined separately for the left and right legs, and jump performances were only compared within each leg (i.e. when the left-leg stance mSEBT was used to split the groups, only left-leg jumps were compared, and the same for the right leg). Effect sizes (d) were also calculated, where the difference between the means was divided by the pooled standard deviations (Cohen, 1988). A $d$ less than 0.2 was considered a trivial effect; 0.2 to 0.6 a small effect; 0.6 to 1.2 a moderate effect; 1.2 to 2.0 a large effect; 2.0 to 4.0 a very large effect; and 4.0 and above an extremely large effect (Hopkins, 2004).

\section{Results}

The correlations for the mSEBT and jumps are shown in Table 1. There were three significant relationships for the left leg. Vertical jump power correlated with the posteromedial and medial excursions, and lateral jump distance correlated with the medial excursion. Each of these correlations was moderate. There were also four significant, moderate relationships for the right leg. Standing broad jump distance correlated with the posteromedial and anteromedial excursions. Relative standing broad jump and lateral jump also correlated with the anteromedial excursion. The seven significant relationships were all positive, indicating a greater excursion distance related to a superior jump performance. 


\section{Table 1}

Correlations between the posteromedial, medial, and anteromedial reach distances in the modified Star Excursion Balance (mSEBT) test when each leg was used for stance, and the left- and right-leg vertical jump, standing broad jump, and lateral jump in recreational male team sport athletes $(n=32) . r=$ correlation coefficient. $p=$ significance .

\begin{tabular}{|c|c|c|c|c|}
\hline & & Posteromedial & Medial & Anteromedial \\
\hline \multicolumn{5}{|c|}{ Left-Leg Stance mSEBT and Left-Leg Jump Correlations } \\
\hline \multirow{2}{*}{ Vertical Jump } & $\mathrm{r}$ & 0.22 & 0.28 & 0.20 \\
\hline & $p$ & 0.22 & 0.12 & 0.29 \\
\hline \multirow{2}{*}{ Vertical Jump Power } & $\mathrm{r}$ & 0.39 & 0.35 & -0.28 \\
\hline & $p$ & $0.03 *$ & $0.05^{*}$ & 0.12 \\
\hline \multirow{2}{*}{$\begin{array}{l}\text { Standing Broad } \\
\text { Jump }\end{array}$} & $\mathrm{r}$ & 0.08 & 0.33 & 0.15 \\
\hline & $p$ & 0.67 & 0.07 & 0.43 \\
\hline \multirow{2}{*}{$\begin{array}{l}\text { Relative Standing } \\
\text { Broad Jump }\end{array}$} & $\mathrm{r}$ & -0.16 & 0.10 & 0.32 \\
\hline & $p$ & 0.38 & 0.58 & 0.07 \\
\hline \multirow{2}{*}{ Lateral Jump } & $\mathrm{r}$ & 0.20 & 0.45 & 0.07 \\
\hline & $p$ & 0.29 & $0.01 *$ & 0.72 \\
\hline \multirow{2}{*}{ Relative Lateral Jump } & $\mathrm{r}$ & -0.07 & 0.21 & 0.29 \\
\hline & $p$ & 0.72 & 0.25 & 0.11 \\
\hline \multicolumn{5}{|c|}{ Right-Leg Stance mSEBT and Right-Leg Jump Correlations } \\
\hline \multirow{2}{*}{ Vertical Jump } & $\mathrm{r}$ & 0.17 & 0.11 & 0.30 \\
\hline & $p$ & 0.34 & 0.54 & 0.10 \\
\hline \multirow{2}{*}{ Vertical Jump Power } & $\mathrm{r}$ & 0.07 & 0.17 & -0.32 \\
\hline & $p$ & 0.71 & 0.36 & 0.08 \\
\hline \multirow{2}{*}{$\begin{array}{l}\text { Standing Broad } \\
\text { Jump }\end{array}$} & $\mathrm{r}$ & 0.38 & 0.31 & 0.42 \\
\hline & $p$ & $0.03 *$ & 0.08 & $0.02 *$ \\
\hline \multirow{2}{*}{$\begin{array}{c}\text { Relative Standing } \\
\text { Broad Jump }\end{array}$} & $\mathrm{r}$ & $<0.01$ & 0.23 & 0.42 \\
\hline & $p$ & 1.00 & 0.22 & $0.02 *$ \\
\hline \multirow{2}{*}{ Lateral Jump } & $\mathrm{r}$ & 0.33 & 0.20 & 0.34 \\
\hline & $p$ & 0.06 & 0.26 & 0.06 \\
\hline \multirow{2}{*}{ Relative Lateral Jump } & $\mathrm{r}$ & -0.02 & 0.19 & 0.35 \\
\hline & $p$ & 0.92 & 0.30 & $0.05 *$ \\
\hline
\end{tabular}

Note: $*$ Significant $(p \leq 0.05)$ relationship between variables. 
There were no significant between-group differences in age (better $=23.17$ \pm 4.11 years; lesser $=22.65 \pm 3.87$ years; $p=0.72 ; d=0.13$ ), height (better $=1.80 \pm 0.09 \mathrm{~m}$; lesser $=1.79 \pm 0.06 \mathrm{~m} ; p=0.80 ; d=0.13)$, or body mass (better $=81.85 \pm 11.45 \mathrm{~kg}$; lesser $=77.89 \pm 13.13 \mathrm{~kg} ; p=0.39 ; d=0.32$ ) when participants were split into better $(n=12)$ and lesser $(n=20)$ dynamic stability groups according to the left-leg stance mSEBT scores (Table 2). The better group reached significantly further in the posteromedial and medial, but not anteromedial, directions. There were no significant differences when comparing performance of the three left-leg jumps between the groups. There was a moderate effect for the $13 \%$ greater vertical jump power for the better group, although the difference was not significant.

\section{Table 2}

Excursions distances (posteromedial, medial, anteromedial, and sum of the three distances) in the modified Star Excursion Balance Test (mSEBT) when the left leg was used for stance, and left-leg vertical jump, standing broad jump (SBJ), and lateral jump performance, by better (n $=12)$ and lesser $(n=20)$ dynamic stability groups defined by performance in the mSEBT in recreational male team sport atbletes. All excursion distances were expressed as a percentage of leg length. All jumps were measured in meters. $p=$ significance. $d=$ effect size

\begin{tabular}{cccccc}
\hline & Better Group & Lesser Group & p value & d & d Strength \\
\hline Posteromedial & $92.64 \pm 3.71$ & $80.62 \pm 5.21^{*}$ & $<0.01$ & 2.61 & Very Large \\
Medial & $87.11 \pm 3.08$ & $72.03 \pm 8.26^{*}$ & $<0.01$ & 2.42 & Very Large \\
Anteromedial & $74.98 \pm 6.75$ & $72.53 \pm 6.59$ & 0.32 & 0.37 & Small \\
Sum of Excursions & $254.73 \pm 9.91$ & $225.18 \pm 12.27^{*}$ & $<0.01$ & 2.65 & Very Large \\
Vertical Jump & $0.41 \pm 0.05$ & $0.37 \pm 0.09$ & 0.25 & 0.55 & Small \\
Vertical Jump Power & $1168.76 \pm 169.91$ & $1033.00 \pm 195.41$ & 0.06 & 0.74 & Moderate \\
SBJ & $2.09 \pm 0.16$ & $2.04 \pm 0.27$ & 0.58 & 0.23 & Small \\
Relative SBJ & $0.027 \pm 0.005$ & $0.027 \pm 0.006$ & 0.98 & 0.00 & Trivial \\
Lateral Jump & $1.96 \pm 0.12$ & $1.83 \pm 0.31$ & 0.20 & 0.55 & Small \\
Relative Lateral Jump & $0.025 \pm 0.004$ & $0.024 \pm 0.006$ & 0.77 & 0.20 & Small \\
\hline
\end{tabular}

Note: $*$ Significantly $(p \leq 0.05)$ less than the better dynamic stability group.

There were no significant between-group differences in age (better $=23.27$ \pm 3.81 years; lesser $=22.47 \pm 4.06$ years; $p=0.57 ; d=0.20$ ), height (better $=1.80 \pm 0.07 \mathrm{~m}$; lesser $=1.79 \pm 0.08 \mathrm{~m} ; p=0.93 ; d=0.13)$, or body mass (better $=77.26 \pm 11.20 \mathrm{~kg}$; lesser $=81.24 \pm 13.59 \mathrm{~kg} ; p=0.38 ; d=0.32$ ) when participants were split into better $(n=15)$ and lesser $(n=17)$ dynamic stability 
groups according to right-leg stance mSEBT (Table 3). The better group reached significantly further in all directions. There were no significant differences in jump performance, and all effects were small.

\section{Table 3}

Excursions distances (posteromedial, medial, anteromedial, and sum of the three distances) in the modified Star Excursion Balance Test (mSEBT) when the right leg was used for stance, and right-leg vertical jump, standing broad jump (SBJ), and lateral jump performance, by better $(n=15)$ and lesser $(n=17)$ dynamic stability groups defined by performance in the mSEBT in recreational male team sport athletes. All excursion distances were expressed as a percentage of leg length. All jumps were measured in meters. $p=$ significance. $d=$ effect size

\begin{tabular}{cccccc}
\hline & Better Group & Lesser Group & $p$ value & $d$ & $d$ Strength \\
\hline Posteromedial & $93.19 \pm 5.08$ & $82.93 \pm 5.37^{*}$ & $<0.01$ & 1.96 & Large \\
Medial & $82.79 \pm 6.70$ & $74.28 \pm 7.46^{*}$ & $<0.01$ & 1.20 & Large \\
Anteromedial & $78.21 \pm 5.77$ & $71.81 \pm 6.19^{*}$ & 0.01 & 1.07 & Moderate \\
Sum of Excursions & $254.19 \pm 8.65$ & $229.02 \pm 14.23^{*}$ & $<0.01$ & 2.14 & Very Large \\
Vertical Jump & $0.40 \pm 0.09$ & $0.39 \pm 0.06$ & 0.70 & 0.13 & Small \\
Vertical Jump Power & $1050.37 \pm 179.88$ & $1134.53 \pm 189.67$ & 0.21 & 0.46 & Small \\
SBJ & $2.06 \pm 0.17$ & $1.98 \pm 0.18$ & 0.17 & 0.46 & Small \\
Relative SBJ & $0.027 \pm 0.004$ & $0.025 \pm 0.005$ & 0.84 & 0.44 & Small \\
Lateral Jump & $1.88 \pm 0.20$ & $1.78 \pm 0.23$ & 0.21 & 0.46 & Small \\
Relative Lateral Jump & $0.024 \pm 0.004$ & $0.023 \pm 0.005$ & 0.51 & 0.22 & Small \\
\hline
\end{tabular}

Note: * Significantly $(\not \leq 0.05)$ less than the better dynamic stability group.

\section{Discussion}

This study analyzed the relationships between dynamic stability as measured by the mSEBT with measures of unilateral jump performance. The ability to maintain balance during the preparation phase prior to a single-leg jump should allow for greater range of motion and force development during stance, which can lead to a superior jump performance (Domire and Challis, 2007). Despite this, only seven out of a 36 correlations were found to be significant when comparing excursion distances and jump performance (Table 1). There were no significant differences in jump performance between better and lesser dynamic stability groups (Tables 2 and 3). These findings were counter to the original 
hypotheses for this research, in that it appears there are limited relationships between unilateral dynamic stability and jump performance. Nonetheless, the results from this study demonstrate and reinforce the complex relationship between physiological and biomechanical capacities for unilateral multidirectional movements.

The current study did provide some support for Lockie et al. (2013b). Large correlations were found by Lockie et al. (2013b) between certain SEBT reaches (lateral, posterolateral, posterior, posteromedial, medial) and lateral jump performance. However, when the mSEBT was used in this research, which eliminated redundant excursions and makes the test a more specific dynamic stability assessment (Hertel et al., 2006), significant correlations with unilateral jump performance were limited. Seven moderate correlations were found (Table 1). These included the: posteromedial and medial excursions with left-leg vertical jump power; medial excursion and left-leg lateral jump; posteromedial excursion and right-leg standing broad jump; and anteromedial excursion and right-leg relative standing broad and lateral jumps. Lockie et al. (2013b) suggested that similarities in joint mobility and muscle recruitment would contribute to relationships between certain excursions and unilateral jumping. Additionally, the relationships documented for vertical jump power, and the relative standing broad and lateral jumps, highlight the importance of not just jump height or distace, but the ability to project the body relative to an athlete's body mass (Cronin and Hansen, 2005; Lockie et al., 2012a; Nimphius et al., 2010; Stockbrugger and Haennel, 2003). Nevertheless, correlation analyses do have limitations, in that factors such as participant body mass, physique, flexibility, technique, and strength has an effect on the statistical models that result (Brughelli et al., 2008). As previously stated, in addition to lower-body dynamic stability, strength (Alemdaroglu, 2012; Baker and Nance, 1999; Wisløff et al., 2004), rate of force development (Häkkinen and Komi, 1985; Häkkinen et al., 1986), use of elastic energy (Häkkinen et al., 1986; Harrison et al., 2004), leg stiffness (Harrison et al., 2004; Hunter and Marshall, 2002; Pruyn et al., 2014), and technique (Bobbert and van Ingen Schenau, 1988; Harman et al., 1990; Hudson, 1986) all contribute to jump performance and power generation. The combination of these physiological, biomechanical, and technical factors would have influenced the breadth and strength of correlations between the mSEBT and unilateral jumping found in this study. Nonetheless, as there were some significant relationships, these results do illustrate that dynamic stability does provide some contribution to unilateral jump performance in recreational male team sport athletes.

Despite these results, when participants were split into better and lesser dynamic stability groups, there were no significant differences in jump performance, and any differences that did exist only had small effects (Tables 
2 and 3). There was a moderate difference in the greater left-leg vertical jump power generated by the in the better group when compared to the lesser group, further highlighting the importance of relative power production (Cronin and Hansen, 2005; Lockie et al., 2012a; Nimphius et al., 2010; Stockbrugger and Haennel, 2003). Nevertheless, this between-group difference was not significant. These results suggest that a recreational team sport athlete with better dynamic stability capacities may not always be able to demonstrate this within a maximal unilateral jump. Taken together with the correlation data, team sport and strength and conditioning coaches should infer that within the training programs they administer for their athlete, they must ensure they incorporate exercises that can emphasize dynamic stability and greater power generation. Purely facilitating unilateral jumps without a specific focus on dynamic stability or maximal power may not develop both capacities concurrently. From a practical perspective, exercises such hop-and-holds, or using unstable surfaces for strength exercises, can improve dynamic stability in athletes (Myer et al., 2006). Explosive, maximal plyometrics exercises, performed in conjunction with speed and agility exercises, can improve jump performance and multidirectional movement patterns in experienced team sport athletes (Jovanovic et al., 2011; Lockie et al., 2014b). Strength and conditioning coaches should include specific dynamic stability and single-leg jump exercises within a team sport athlete's program to ensure both of these capacities are enhanced.

Interestingly, although the participants were divided into groups of different dynamic stability capabilities, there were still differences in the extent of this for each leg. For example, even though the better group was significantly superior in the posteromedial and medial excursions when the left leg was used for stance in the mSEBT, they were not for the anteromedial excursion (Table 3). This excursion is relatively difficult, as the participant needs to reach in front of their body, which is why it was included in the mSEBT (Hertel et al., 2006). These results reinforce the notion that each leg can display different neuromuscular capabilities, even in healthy athletic populations. Indeed, this is why the legs were analyzed as left and right, rather than dominant and non-dominant. This was primarily because that depending on the assessment, the leg that could be defined as 'dominant' may be task-dependent. This is especially true for balance tasks such as the mSEBT, as the dominant leg defined by the mSEBT could differ from that defined by a jump (Gstottner et al., 2009; McCurdy and Langford, 2006; McGrath et al., 2015). The practical application of this finding is that perceived leg dominance for an athlete may not crossover between different athletic tasks. Further, to ensure the appropriate development of dynamic stability and leg power in each leg, strength and conditioning coaches should include unilateral lower-body exercises, with a balance between exercises prescribed for the left and right legs. 
There were limitations to this study that should be acknowledged. This research utilized unilateral take-offs and bilateral landings to examine leg power. Unilateral landings may be more greatly influenced by dynamic stability, despite the prospective importance of dynamic stability on the preparation phase of a jump (Domire and Challis, 2007). Additionally, only one measure of dynamic stability was used, and other dynamic stability assessments such as hop-andbalance tests (Myer et al., 2006) or the Y-balance test (Teyhen et al., 2014) may potentially better relate to unilateral jump performance. Nonetheless, the SEBT (Gribble, 2003; Hertel et al., 2000; Lockie et al., 2013b) and mSEBT (Hertel et al., 2006; Lockie et al., 2014b) are valid tests of dynamic stability. Recreational team sport athletes were also the only participants recruited for this study. Elite athletes may demonstrate different relationships between unilateral dynamic stability and jump performance, which should be investigated in future research.

\section{Conclusions}

In conclusion, this study found limited relationships between unilateral dynamic stability as measured by the mSEBT, and multidirectional jump performance. The data provided some indication of the contribution of dynamic stability to unilateral leg power. Nevertheless, the results of this research further highlights the complex interaction between physiological, biomechanical, and technical factors that interact within lower-body multidirectional movements. Further to this, recreational team sport athletes that demonstrated superior dynamic stability did not perform significantly better in unilateral jumps. Strength and conditioning coaches for team sports should incorporate exercises that develop unilateral dynamic stability (e.g. hop-and-holds) and leg power (e.g. plyometrics emphasizing explosive take-offs) into their training programs, as these factors may not always be enhanced concurrently within one exercise. Coaches should also make sure that there is a balance in the exercises prescribed for the left and right legs. This should ensure the development of dynamic stability and jump and power capacities for each leg specific to a team sport athlete.

\section{Acknowledgements}

We would like to acknowledge our participants for their contribution to the study. This research project received no external financial assistance. None of the authors have any conflict of interest. 


\section{References}

Alemdaroglu, U. (2012). The relationship between muscle strength, anaerobic performance, agility, sprint ability and vertical jump performance in professional basketball players. Journal of Human Kinetics, 31, 149-158.

Baker, D., \& Nance, S. (1999). The relation between strength and power in professional rugby league players. Journal of Strength and Conditioning Research, 13, 224-229.

Bobbert, M. F., \& van Ingen Schenau, G. J. (1988). Coordination in vertical jumping. Journal of Biomechanics, 21, 249-262.

Brughelli, M., Cronin, J., Levin, G., \& Chaouachi, A. (2008). Understanding change of direction ability in sport. Sports Medicine, 38, 1045-1063.

Burr, J. F., Jamnik, V. K., Dogra, S., \& Gledhill, N. (2007). Evaluation of jump protocols to assess leg power and predict hockey playing potential. Journal of Strength and Conditioning Research, 21, 1139-1145.

Cohen, J. (1988). Statistical Power Analysis for the Behavioral Sciences (2 ${ }^{\text {nd }}$ ed.). Hillsdale, New Jersey: Lawrence Earlbaum Associates.

Cronin, J. B., \& Hansen, K. T. (2005). Strength and power predictors of sports speed. Journal of Strength and Conditioning Research, 19, 349-357.

Delaney, J. A., Scott, T. J., Ballard, D. A., Duthie, G. M., Hickmans, J. A., Lockie, R. G., \& Dascombe, B. J. (in press). Contributing factors to change-of-direction ability in professional rugby league players. Journal of Strength and Conditioning Research, Publish Ahead of Print: doi: 10.1519/JSC.0000000000000960.

Delextrat, A., \& Cohen, D. (2009). Strength, power, speed, and agility of women basketball players according to playing position. Journal of Strength and Conditioning Research, 23, 1974-1981.

Domire, Z. J., \& Challis, J. H. (2007). The influence of squat depth on maximal vertical jump performance. Journal of Sports Science, 25, 193-200.

Gabbett, T. J., \& Seibold, A. J. (2013). Relationship between tests of physical qualities, team selection, and physical match performance in semiprofessional rugby league players. Journal of Strength and Conditioning Research, 27, 3259-3265. 
Gribble, P. (2003). The star excursion balance test as a measurement tool. Athletic Therapy Today, 8, 46-47.

Gribble, P. A., \& Hertel, J. (2003). Considerations for normalizing measures of the Star Excursion Balance Test. Measurement in Physical Education and Exercise Science, 7, 89-100.

Gribble, P. A., Hertel, J., \& Plisky, P. (2012). Using the Star Excursion Balance Test to assess dynamic postural-control deficits and outcomes in lower extremity injury: a literature and systematic review. Journal of Athletic Training, 47, 339-357.

Gstottner, M., Neher, A., Scholtz, A., Millonig, M., Lembert, S., \& Raschner, C. (2009). Balance ability and muscle response of the preferred and nonpreferred leg in soccer players. Motor Control, 13, 218-231.

Häkkinen, K., \& Komi, P. V. (1985). Effect of explosive type strength training on electromyographic and force production characteristics of leg extensor muscles during concentric and various stretch-shortening cycle exercises. Scandinavian Journal of Sports Sciences, 7, 65-76.

Häkkinen, K., Komi, P. V., \& Kauhanen, H. (1986). Electromyographic and force production characteristics of leg extensor muscles of elite weight lifters during isometric, concentric, and various stretch-shortening cycle exercises. International Journal of Sports Medicine, 7, 144-151.

Harman, E. A., Rosenstein, M. T., Frykman, P. N., \& Rosenstein, R. M. (1990). The effects of arms and countermovement on vertical jumping. Medicine and Science in Sports and Exercise, 22, 825-833.

Harrison, A. J., Keane, S. P., \& Coglan, J. (2004). Force-velocity relationship and stretch-shortening cycle function in sprint and endurance athletes. Journal of Strength and Conditioning Research, 18, 473-479.

Hertel, J., Braham, R. A., Hale, S. A., \& Olmsted-Kramer, L. C. (2006). Simplifying the Star Excursion Balance Test: analyses of subjects with and without chronic ankle instability. Journal of Orthopaedic and Sports Physical Therapy, 36, 131-137.

Hertel, J., Miller, S. J., \& Denegar, C. R. (2000). Intratester and intertester during the Star Excursion Balance Tests. Journal of Sport Rehabilitation, 9, 104-116. 
Hopkins, W. G. (2004). How to interpret changes in an athletic performance test. Sportscience, 8, 1-7.

Hopkins, W. G. (2009). A scale of magnitude for effect statistics. www.sportsci.org/ resource/stats/index.html.

Hudson, J. L. (1986). Coordination of segments in the vertical jump. Medicine and Science in Sports and Exercise, 18, 242-251.

Hunter, J. P., \& Marshall, R. N. (2002). Effects of power and flexibility training on vertical jump technique. Medicine and Science in Sports and Exercise, 34, 478486.

Jovanovic, M., Sporis, G., Omrcen, D., \& Fiorentini, F. (2011). Effects of speed, agility, quickness training method on power performance in elite soccer players. Journal of Strength and Conditioning Research, 25, 1285-1292.

Kovacs, M. S., Roetert, E. P., Ellenbecker, T. S. (2008). Efficient deceleration: the forgotten factor in tennis-specific training. Strength and Conditioning Journal, 30, 58-69.

Kuzmits, F. E., Adams, A. J. (2008). The NFL combine: does it predict performance in the National Football League? Journal of Strength and Conditioning Research, 22, 1721-1727.

Lockie, R. G., Callaghan, S. J., Berry, S. P., Cooke, E. R., Jordan, C. A., Luczo, T. M., \& Jeffriess, M. D. (2014a). Relationship between unilateral jumping ability and asymmetry on multidirectional speed in team-sport athletes. Journal of Strength and Conditioning Research, 28, 3557-3566.

Lockie, R. G., Jeffriess, M. D., Schultz, A. B., \& Callaghan, S. J. (2012a). Relationship between absolute and relative power with linear and change-of-direction speed in junior American football players from Australia. Journal of Australian Strength and Conditioning, 20, 4-12.

Lockie, R. G., Schultz, A. B., Callaghan, S. J., \& Jeffriess, M. D. (2012b). Physiological profile of national-level junior American football players in Australia. Serbian Journal of Sports Sciences, 6, 127-136.

Lockie, R. G., Schultz, A. B., Callaghan, S. J., \& Jeffriess, M. D. (2013a). The effects of isokinetic knee extensor and flexor strength on dynamic stability as measured by functional reaching. Isokinetics and Exercise Science, 21, 301-309. 
Lockie, R. G., Schultz, A. B., Callaghan, S. J., \& Jeffriess, M. D. (2014b). The effects of traditional and enforced stopping speed and agility training on multidirectional speed and athletic performance. Journal of Strength and Conditioning Research, 28, 1538-1551.

Lockie, R. G., Schultz, A. B., Callaghan, S. J., \& Jeffriess, M. D. (in press). The relationship between dynamic stability and multidirectional speed. Journal of Strength and Conditioning Research, Publish Ahead of Print: doi: 10.1519/ JSC.1510b1013e3182a1744b1516.

Lockie, R. G., Schultz, A. B., Callaghan, S. J., Jordan, C. A., Luczo, T. M., \& Jeffriess, M. D. (2015a). A preliminary investigation into the relationship between functional movement screen scores and athletic physical performance in female team sport athletes. Biology of Sport, 32, 41-51.

Lockie, R. G., Schultz, A. B., Jordan, C. A., Callaghan, S. J., Jeffriess, M. D., \& Luczo, T. M. (2015b). Can selected functional movement screen assessments be used to identify movement deficiencies that could affect multidirectional speed and jump performance? Journal of Strength and Conditioning Research, 29, 195-205.

Lockie, R. G., Schultz, A. B., Luczo, T. M., Callaghan, S. J., \& Jeffriess, M. D. (2013b). Effect of unilateral dynamic stability on lateral jump performance in team sport athletes. Serbian Journal of Sports Sciences, 7, 159-166.

Markovic, G. (2007). Poor relationship between strength and power qualities and agility performance. Journal of Sports Medicine and Physical Fitness, 47, 276-283.

McClenton, L. S., Brown, L. E., Coburn, J. W., \& Kersey, R. D. (2008). The effect of short-term VertiMax vs. depth jump training on vertical jump performance. Journal of Strength and Conditioning Research, 22, 321-325.

McCurdy, K., \& Langford, G. (2006). The relationship between maximum unilateral squat strength and balance in young adult men and women. Journal of Sports Science and Medicine, 5, 282-288.

McCurdy, K. W., Langford, G. A., Doscher, M. W., Wiley, L. P., \& Mallard, K. G. (2005). The effects of short-term unilateral and bilateral lower-body resistance training on measures of strength and power. Journal of Strength and Conditioning Research, 19, 9-15. 
McElveen, M. T., Riemann, B. L., \& Davies, G. J. (2010). Bilateral comparison of propulsion mechanics during single-leg vertical jumping. Journal of Strength and Conditioning Research, 24, 375-381.

McGrath, T. M., Waddington, G., Scarvell, J. M., Ball, N. B., Creer, R., Woods, K., \& Smith, D. (2015). The effect of limb dominance on lower limb functional performance - a systematic review. Journal of Sports Sciences,1-14.

Meylan, C., McMaster, T., Cronin, J., Mohammad, N. I., Rogers, C., Deklerk, M. (2009). Single-leg lateral, horizontal, and vertical jump assessment: reliability, interrelationships, and ability to predict sprint and change-of-direction performance. Journal of Strength and Conditioning Research, 23, 1140-1147.

Mornieux, G., Gehring, D., Tokuno, C., Gollhofer, A., \& Taube, W. (2014). Changes in leg kinematics in response to unpredictability in lateral jump execution. European Journal of Sport Science, 14, 678-685.

Myer, G. D., Ford, K. R., Brent, J. L., \& Hewett, T. E. (2006). The effects of plyometric vs. dynamic stabilization and balance training on power, balance, and landing force in female athletes. Journal of Strength and Conditioning Research, $20,345-353$.

Newton, R. U., Gerber, A., Nimphius, S., Shim, J. K., Doan, B. K., Robertson, M., Pearson, D. R., Craig, B. W., Hakkinen, K., \& Kraemer, W. J. (2006). Determination of functional strength imbalance of the lower extremities. Journal of Strength and Conditioning Research, 20, 971-977.

Nimphius, S., McGuigan, M. R., \& Newton, R. U. (2010). Relationship between strength, power, speed, and change of direction performance of female softball players. Journal of Strength and Conditioning Research, 24, 885-895.

Peterson, M. D., Alvar, B. A., \& Rhea, M. R. (2006). The contribution of maximal force production to explosive movement among young collegiate athletes. Journal of Strength and Conditioning Research, 20, 867-873.

Pruyn, E. C., Watsford, M., \& Murphy, A. (2014). The relationship between lower-body stiffness and dynamic performance. Applied Physiology, Nutrition and Metabolism, 39, 1144-1150.

Robbins, D. W. (2010). The National Football League (NFL) combine: does normalized data better predict performance in the NFL draft? Journal of Strength and Conditioning Research, 24, 2888-2899. 
Sassi, R. H., Dardouri, W., Yahmed, M. H., Gmada, N., Mahfoudhi, M. E., \& Gharbi, Z. (2009). Relative and absolute reliability of a modified agility T-test and its relationship with vertical jump and straight sprint. Journal of Strength and Conditioning Research, 23, 1644-1651.

Sheppard, J. M., \& Young, W. B. (2006). Agility literature review: classifications, training and testing. Journal of Sports Sciences, 24, 919-932.

Spinks, C. D., Murphy, A. J., Spinks, W. L., \& Lockie, R. G. (2007). Effects of resisted sprint training on acceleration performance and kinematics in soccer, rugby union and Australian football players. Journal of Strength and Conditioning Research, 21, 77-85.

Spiteri, T., Cochrane, J. L., Hart, N. H., Haff, G. G., \& Nimphius, S. (2013). Effect of strength on plant foot kinetics and kinematics during a change of direction task. European Journal of Sport Science, 13, 646-652.

Stockbrugger, B. A., \& Haennel, R. G. (2001). Validity and reliability of a medicine ball explosive power test. Journal of Strength and Conditioning Research, 15, 431438.

Stockbrugger, B. A., \& Haennel, R. G. (2003). Contributing factors to performance of a medicine ball explosive power test: a comparison between jump and nonjump athletes. Journal of Strength and Conditioning Research, 17, 768-774.

Teyhen, D. S., Shaffer, S. W., Lorenson, C. L., Greenberg, M. D., Rogers, S. M., Koreerat, C. M., Villena, S. L., Zosel, K. L., Walker, M. J., \& Childs, J. C. (2014). Clinical measures associated with dynamic balance and functional movement. Journal of Strength and Conditioning Research, 28, 1272-1283.

Wikstrom, E. A., Tillman, M. D., Smith, A. N., \& Borsa, P. A. (2005). A new force-plate technology measure of dynamic postural stability: the dynamic postural stability index. Journal of Athletic Training, 40, 305-309.

Wisløff, U., Castagna, C., Helgerud, J., Jones, R., \& Hoff, J. (2004). Strong correlation of maximal squat strength with sprint performance and vertical jump height in elite soccer players. British Journal of Sports Medicine, 38, 285-288. 
Robert LOCKIE, $\mathrm{PhD}$, is currently an assistant professor in biomechanics and strength and conditioning at California State University, Northridge. Robert earned his $\mathrm{PhD}$, in which he investigated sprint acceleration technique, and speed, strength, and power training in field sport athletes, at the University of Technology, Sydney. Since this time, Robert has conducted research into linear speed, change-of-direction speed, and agility; sprint technique; sports biomechanics; team sport analysis; and strength and conditioning.

\section{Corresponding Author}

Dr. Robert Lockie

California State University, Northridge

Department of Kinesiology

18111 Nordhoff Street

Northridge, CA 91330

USA

Phone (international): +1 818-677-6983

Fax (international): +1 818-677-3207

Email: robert.lockie@csun.edu

Farzad JALILVAND is currently the strength and conditioning coach at Granada Hills Charter High School in Los Angeles, and also lectures in kinesiology at California State University, Northridge. He completed his Masters in exercise physiology at California State University, Northridge, and has conducted research in soccer and team sport performance. Farzad can be contacted at: farzad.tehrani@csun.edu.

Corrin JORDAN is currently an accredited exercise physiologist with Konekt Rehabilitation Services in Wollongong. She completed her Masters in exercise physiology at Charles Sturt University. Corrin assisted with research into movement screening and athletic performance at the University of Newcastle. She can be contacted at: corrin. jordan@uon.edu.au.

Samuel CALLAGHAN is currently completing his $\mathrm{PhD}$ at Edith Cowan University, where he is investigating the biomechanics of cricket fast bowling, and strength training for cricketers. He completed his Honours investigating the kinematics of the cricket quick single at the University of Newcastle. Samuel has also conducted research into team sports; sports biomechanics; and strength and conditioning. He can be contacted at: scallag5@our.ecu.edu.au.

Matthew JEFFRIESS is currently completing his $\mathrm{PhD}$ at the University of Technology, Sydney, where he is investigating the physiology, training, and decision-making of rugby league referees. He completed his Honours investigating the effects of ankle taping on planned change-of-direction and reactive agility in basketballers at the University of 
Newcastle. Matthew has also conducted research into team sports; sports biomechanics; and strength and conditioning. He can be contacted at: mjeffriess@nrl.com.au.

Tawni LUCZO is currently completing her Masters in Athletic Training at Florida International University. She attained her bachelor's degree in kinesiology at California State University, Monterey Bay. Tawni assisted with research into movement screening and athletic performance at the University of Newcastle. She can be contacted at: tluczo@csumb.edu.

Adrian SCHULTZ is currently a lecturer in exercise and sport science at the University of Newcastle. He is also completing his $\mathrm{PhD}$ at this institution, where he is investigating low back pain, injury mechanics, and hiking technique in elite sailors. He completed his Masters at the University of Port Elizabeth, and has conducted research into the biomechanics of sprint acceleration and deceleration; linear speed, change-of-direction speed, and agility; developing athletes; and strength and conditioning. Adrian can be contacted at: adrian.schultz@newcastle.edu.au. 
